\section{Response to: 'Correspondence on 'Safety and tolerability of nintedanib in patients with systemic sclerosis-associated interstitial lung disease: data from the SENSCIS trial" by Bredemeier}

Following the publication of data on the safety and tolerability of nintedanib in the SENSCIS trial, ${ }^{12}$ and INBUILD trial, ${ }^{3}$ Dr Bredemeier has raised the question of the risk of serious respiratory infections with nintedanib treatment in patients with systemic sclerosis-associated interstitial lung disease (SSc-ILD) and other interstitial lung diseases (ILDs). ${ }^{4}$ We have made a thorough investigation into this question and concluded that the evidence from clinical trials does not suggest an increased risk of infections in patients treated with nintedanib. Further, the mechanistic effects of nintedanib, an inhibitor of tyrosine kinases, do not suggest a plausible mechanism by which nintedanib would affect the risk of infection. $^{5}$

We acknowledge that in the SENSCIS trial, there were numerical imbalances between the nintedanib and placebo groups in the percentages of patients with overall serious infections $(6.6 \%$ vs $3.5 \%)$ or serious lower respiratory tract infections $(3.5 \%$ vs $1.7 \%)$. This difference was driven largely by serious adverse events of pneumonia $(2.8 \%(n=8)$ vs $0.3 \%(n=1))$, when pneumonia was defined using the single preferred term 'pneumonia' from the Medical Dictionary for Regulatory Activities. A detailed review of the cases of serious pneumonia in patients treated with nintedanib revealed that none was considered related to nintedanib by the investigator. Most of the cases (6 of 8) occurred after nintedanib had been discontinued and an explanation for the infection was apparent in the majority of cases (predominantly the use of immunosuppressive drugs such as mycophenolate or cyclophosphamide). In the INPULSIS trials in patients with idiopathic pulmonary fibrosis (IPF), ${ }^{6}$ there was no evidence of an increased risk of overall serious infections, serious lower respiratory tract infections or serious pneumonia with nintedanib versus placebo $(8.5 \%$ vs $8.5 \%, 5.6 \%$ vs $5.4 \%$ and $3.6 \%$ vs $3.8 \%$, respectively). Similarly, in the INBUILD trial in patients with progressive fibrosing ILDs other than IPF, the risk of these infections was similar between the nintedanib and placebo groups $(8.7 \%$ vs $8.2 \%, 5.7 \%$ vs $6.3 \%$ and $3.6 \%$ vs $3.3 \%$, respectively).

Dr Bredemeier queries whether nintedanib has a worse safety profile in patients with fibrosing ILDs who do not have a usual interstitial pneumonia (UIP) pattern on high-resolution computed tomography (HRCT). When looking at data from the whole INBUILD trial, in patients who had other fibrotic patterns on HRCT, the frequencies of serious adverse events and fatal adverse events were similar between the nintedanib and placebo groups ( $42.9 \%$ vs $44.8 \%$ and $4.8 \%$ vs $7.2 \%$, respectively). The heterogeneity of the patient population, with various comorbidities and comedications, needs to be borne in mind when interpreting the safety data from the INBUILD trial, but descriptive analyses suggest that nintedanib had a consistent safety profile between subgroups by fibrotic pattern on HRCT. Importantly, both in patients with a UIP-like fibrotic pattern on HRCT and in patients with other fibrotic patterns on HRCT, nintedanib was associated with a significant reduction in the rate of decline in forced vital capacity $(\mathrm{mL} /$ year) over 52 weeks compared with placebo (by $61 \%$ and $49 \%$, respectively). ${ }^{3}$

In conclusion, our analyses indicate that in patients with SSc-ILD and with fibrosing ILDs with a progressive phenotype, nintedanib reduces the rate of progression of ILD, and the totality of the data does not suggest an increased risk of serious infections.

\section{James R Seibold $\odot$,' Veronika Kohlbrenner, ${ }^{2}$ Margarida Alves, ${ }^{3}$ Oliver Distler ${ }^{4}{ }^{4}$ \\ ${ }^{1}$ Scleroderma Research Consultants LLC, Aiken, South Carolina, USA \\ ${ }^{2}$ Boehringer Ingelheim Pharmaceuticals, Inc, Ridgefield, Connecticut, USA \\ ${ }^{3}$ Boehringer Ingelheim International $\mathrm{GmbH}$, Ingelheim am Rhein, Germany \\ ${ }^{4}$ Department of Rheumatology, University Hospital Zurich, Zurich, Switzerland}

Correspondence to Professor James R Seibold, Scleroderma Research Consultants LLC, Aiken, South Carolina, USA; jamesrseibold@gmail.com

Handling editor Josef $S$ Smolen

Acknowledgements The SENSCIS trial was funded by Boehringer Ingelheim. We thank the patients who participated in this trial. Writing assistance, supported financially by Boehringer Ingelheim, was provided by Julie Fleming and Wendy Morris of FleishmanHillard Fishburn, London, UK, during the development of this response letter. The authors were fully responsible for all content and editorial decisions, were involved at all stages of development and provided their approval on the final version. Boehringer Ingelheim was given the opportunity to review the response letter for medical and scientific accuracy as well as intellectual property considerations.

Contributors All authors contributed to the writing of this letter and have approved the final version.

Funding The SENSCIS trial was funded by Boehringer Ingelheim.

Competing interests JRS reports personal fees from Atlantic, Bayer, Blade, Boehringer Ingelheim, Camurus, Corbus, DRG, Eicos, Eiger Pharmaceuticals, EMD Serono, Guidepoint, Indalo, Mitsubishi and Xenikos; and stock ownership or options in BriaCell and Pacific Therapeutics. VK and MA are employees of Boehringer Ingelheim. OD reports grants and personal fees from Actelion, Bayer, Boehringer Ingelheim and Mitsubishi; personal fees from AbbVie, Acceleron Pharma, Anamar, Amgen, Baecon Discovery, Blade Therapeutics, Catenion, CSL Behring, ChemomAb, Curzion Pharmaceuticals, Ergonex, Galapagos NV, Glenmark Pharma, GlaxoSmithKline, Inventiva, Italfarmaco, IQVIA, Lilly, Medac, Medscape, Menarini, Mepha, Merck Sharp \& Dohme, Novartis, Roche, Sanofi, Target BioScience and UCB; personal fees and non-financial support from Pfizer; and patent US8247389; and was a member of the SENSCIS trial steering committee.

Patient and public involvement Patients and/or the public were not involved in the design, or conduct, or reporting or dissemination plans of this research.

\section{Patient consent for publication Not required.}

Ethics approval The study protocol was reviewed and approved by the Independent Ethics Committees and/or Institutional Review Boards of the participating centres. Written informed consent was obtained from all patients before study entry.

Provenance and peer review Commissioned; internally peer reviewed. (c) Author(s) (or their employer(s)) 2020. No commercial re-use. See rights and permissions. Published by BMJ.

\section{Check for updates}

To cite Seibold JR, Kohlbrenner V, Alves M, et al. Ann Rheum Dis Epub ahead of print: [please include Day Month Year]. doi:10.1136/annrheumdis-2020-218960

Received 9 September 2020

Accepted 10 September 2020

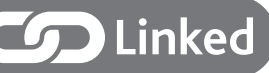

- http://dx.doi.org/10.1136/annrheumdis-2020-218911

Ann Rheum Dis 2020;0:1-2. doi:10.1136/annrheumdis-2020-218960

ORCID iDs

James R Seibold http://orcid.org/0000-0001-5187-3141

Oliver Distler http://orcid.org/0000-0002-0546-8310

\section{REFERENCES}

1 Distler O, Highland KB, Gahlemann M, et al. Nintedanib for systemic sclerosisassociated interstitial lung disease. N Engl J Med 2019;380:2518-28.

2 Seibold JR, Maher TM, Highland KB, et al. Safety and tolerability of nintedanib in patients with systemic sclerosis-associated interstitial lung disease: data from the SENSCIS trial. Ann Rheum Dis 2020. doi:10.1136/annrheumdis-2020-217331. [Epub ahead of print: 05 Aug 2020]. 
3 Flaherty KR, Wells AU, Cottin V, et al. Nintedanib in progressive fibrosing interstitial lung diseases. N Engl J Med 2019;381:1718-27.

4 Bredemeier M. Correspondence on 'Safety and tolerability of nintedanib in patients with systemic sclerosis-associated interstitial lung disease: data from the SENSCIS trial'. Ann Rheum Dis. doi:10.1136/annrheumdis-2020-218911.
5 Wollin L, Distler JHW, Redente EF, et al. Potential of nintedanib in treatment of progressive fibrosing interstitial lung diseases. Eur Respir J 2019;54 doi:10.1183/13993003.00161-2019. [Epub ahead of print: 19 Sep 2019].

6 Richeldi L, du Bois RM, Raghu G, et al. Efficacy and safety of nintedanib in idiopathic pulmonary fibrosis. N Engl J Med 2014;370:2071-82. 